\title{
Emergency room use after being released from incarceration
}

\author{
Erlyana Erlyana', Dennis G Fisher ${ }^{2}$ and Grace L Reynolds ${ }^{3 *}$
}

\begin{abstract}
Background: This study investigates opiate use in mediating the impact of history of incarceration on emergency department (ED) use.

Method: Data were collected from 1,341 clients who underwent HIV and STI screening in an outpatient care center in Long Beach, California. The Risk Behavior Assessment (RBA, baseline) and Risk Behavior Follow-Up Assessment (RBFA, follow-up) were administered to each client with at least a three months interval between assessments.

Results: Of 1341 participants in the study, 931 (69.43\%) reported previous incarceration. Having a history of incarceration was significantly associated with emergency room use as well as a history of sexually transmitted infections (STIS), injection drug use, opiate use, and survival sex trading, defined as sex for money or drugs. The relationship between previous incarceration and ED use was mediated by opiate use for men but not for women. The findings suggested that the effect of history of incarceration on ED use was exacerbated when the individuals were male and opiate users.
\end{abstract}

Conclusions: Targeted interventions in treatment and rehabilitation programs could help prevent unnecessary ED use and reduce the use of EDs through drug treatment during incarceration and after release.

Keywords: Emergency room; Use; Opiate use; Incarceration; Mediation

\section{Background}

Providing adequate support for adjustment after being released from incarceration remains a public health challenge. The magnitude of the unmet health needs and services gaps for inmates and ex-prisoners has been under-studied (Mears \& Cochran, 2012). Uninterrupted access to adequate health care may alleviate negative social and health consequences for former inmates, and improve the success of their reentry to society (Freudenberg et al. 2008; Wang et al. 2012). Receiving continuing and longer periods of substance abuse treatment after being released from prison was positively associated with greater success on parole (LaMoure et al. 2010). In the long run, adequate access to health care may reduce the misuse and spending associated with emergency room (ED) visits for non-emergency cases. Therefore, it is important to investigate patterns of ED use by reentry populations, particularly factors that mediate the use of EDs among individuals with a history of incarceration.

\footnotetext{
* Correspondence: Grace.Reynolds@csulb.edu

${ }^{3}$ Center for Behavioral Research and Services, California State University Long Beach, 1250 Bellflower Blvd., Long Beach, CA 90840, USA

Full list of author information is available at the end of the article
}

\section{Literature review}

Medical care delivered in an ED plays a significant role in the US health care system (it consumed $4 \%$ of all health care spending in 2010). National data show that an average of $20 \%$ of the US population visits an ED each year (Owens et al. 2010) and the total number of visits to EDs increased 34\% from 97 million in 1995 to 130 million in 2010 (a 16\% increase from 37 visits per 100 population to 43 visit per 100 population) while ED supply decreased by $11 \%$ (NCHS, 2013). The ED serves as an entry point for inpatient admissions and is a common setting for acute care. Major challenges, however, have been ED overcrowding, and use of the EDs for non-emergency care by uninsured and underinsured individuals who lack access to primary care providers. California with about 10 million emergency room visits annually (McConville \& Lee, 2008), is potentially facing a bigger challenge with the ruling of the US Supreme Court to reduce overcrowding in California prisons.

Several studies reported that individuals with a history incarceration were more likely to have poor health

\section{它}

(c) 2014 Erlyana et al.; licensee Springer. This is an Open Access article distributed under the terms of the Creative Commons Attribution License (http://creativecommons.org/licenses/by/2.0), which permits unrestricted use, distribution, and reproduction in any medium, provided the original work is properly credited. 
outcomes, high-cost health services use, and low use of regular medical services. A history of incarceration has been associated with a higher prevalence of infectious disease including HIV and STIs; mental illness; and substance abuse and dependency (Davis \& Pacchiana, 2004; Fazel et al. 2006; Fisher et al. 2006; Wilper et al. 2009); a higher prevalence of chronic diseases (Binswanger et al. 2009; Davis \& Pacchiana, 2004; Hawkins et al. 2010; Wang \& Green, 2010), and a higher risk of death (Binswanger et al. 2007). The poor health status of reentry populations also led to use of high-cost health services (Leukefeld et al. 2006). Longer and more severe criminal history was associated with poorer physical health and use of the ED (Mateyoke-Scrivner et al. 2003). Previous studies have shown that the ED was the primary source of care among released prisoners with HIV (Meyer et al. 2012), and drug-involved prisoners (van Olphen et al. 2006). Challenges in accessing health care and medication and risk factors for HIV and hepatitis $\mathrm{C}$ infection $(\mathrm{HCV})$ were more prevalent among former inmates, especially immediately after release (Adams et al. 2011; Hawkins et al. 2010; Kulkarni et al. 2010). The long term effects of incarceration increases the likelihood of poor health (Schnittker \& John, 2007).

Prevalence of substance use and dependence was higher among prisoners than the general population, particularly among drug using women (Fazel et al. 2006). Incarceration and drug use prior to incarceration have been associated with injection drug use among inmates (Calzavara et al. 2003). Prisons may be high-risk environments for the initiation and use of heroin and other drugs (Boys et al. 2002). In addition to being an ongoing challenge for corrections, drug abuse may predispose an individual to misuse or underutilize health services (Leukefeld et al. 1998). Drug abusers were more likely to use the ED (Cherpitel \& Ye, 2008; Gilbert et al. 2012), have higher medical expenses than non-drug abusers (French et al. 2000), and a higher risk of death (Merrall et al. 2010). Illnesses, poorer health status, and use of physical and mental health services were also more common among prisoners who were drug abusers than among non-drug abusing prisoners (Garrity et al. 2002; Kanato, 2008; Webster et al. 2005). The literature also suggests that only heavy illicit drug users were reported to use EDs rather than non-drug users (French et al. 2011) and longer and more frequent drug users were more likely to have unmet health care needs (Narevic et al. 2006). Injection drug users were more likely to visit an ED than non IDUs (Kerr et al. 2005) and frequent drug injectors were more likely to use an ED (Marshall et al. 2012; Stein \& Anderson, 2003). Among women, stigma caused by drug use and incarceration increases the need for health and social services, but restricts access to those services (van Olphen et al. 2009).
Individuals with a history of incarceration (former inmates) were more likely to engage in risky sexual behavior (unprotected sex and transactional sex), immediately upon release (Adams et al. 2011). Arrest and incarceration are temporally associated with and contribute to sexually risky behavior (Epperson et al., 2009). Incarceration was associated with high-risk sex partnerships and acquisition of sexually transmitted infections (STI) and human immunodeficiency virus (HIV; (Fisher et al. 2004; Jenness et al. 2011; Khan et al. 2009; Weiser et al. 2006). Sex trade involvement was associated with having abscesses among injection drug users (Lloyd-Smith et al. 2005) and due to occupational stigma, sex workers were reported to lack access to health care (Lazarus et al. 2011). Other barriers to receiving health care include structural (poverty, homelessness) and individual factors such as drug use, fear of violent victimization, and mental illness (Kurtz et al. 2005). Having multiple sex partners was a significant predictor of ED visits (El-Bassel et al. 2007). This study investigates whether the impact of history of incarceration on ED use is mediated by opiate use and sex trading for drugs or money, two current public health problems with substantial risks to individual health.

\section{Methods}

\section{Datasets}

Data were collected from clients who presented for HIV and STD screening in an outpatient care center in Long Beach, California. Each client was interviewed using two different instruments: the Risk Behavior Assessment (RBA, baseline), and the Risk Behavior Follow-Up Assessment (RBFA, follow-up) with at least a three-month interval between administration of the RBA and RBFA. The RBA elicits information on drug utilization (use of any type of drugs in the last month, use of injected drugs, and frequency of use), sex trading practices, and history of incarceration (including length of time in jail or prison). The RBA has been shown to have good reliability and validity (Dowling-Guyer et al. 1994; Fisher et al. 2004). The RBFA elicits information on use of an emergency room in the last three months and number of hospitalization days during that period (Johnson et al. 2000). Other information collected included age, gender, sexual orientation, race, marital status, educational attainment, living arrangements, homelessness, and income. The RBA-RBFA system was originally developed by grantees funded by the National Institute on Drug Abuse (NIDA) along with NIDA staff from the Community Research Branch. There were 23 grantees in this NIDA Cooperative Agreement. Most of the Cooperative Agreement data used a 6-month follow-up period, but did not find any differences between conditions at follow-up. Because of this, the sites that were funded in the last round of funding developed a 3-month version of the RBFA to 
better detect differences that might occur in this shorter time period, but might dissipate on longer follow-up. Two of the authors on the current study have been very interested in this question of 3 versus 6 month recall period and published a meta-analysis on this topic (Napper et al. 2010). In this meta-analysis, it was found that the reliabilities for most sex behaviors and most drug use were better with the shorter recall period. Therefore this study used the 3-month recall period to maximize reliability.

\section{Participants}

The present study recruited participants through the Center for Behavioral Research and Services (CBRS) in Long Beach, California. In order to be eligible, participants had to have been at least 18 years of age at the time of interview and have photo identification, which also included their date of birth. The study used a sample of participants that come to CBRS who wish to be tested for HIV, hepatitis B, hepatitis C, and/or syphilis. The sample also consisted of participants recruited through snowball sampling, as many participants refer others into testing. Additionally, recruitment came from other programs in the community encouraging HIV and STD testing. Such programs included drug and alcohol treatment programs including the Substance Abuse Foundation (SAF) located in Long Beach. Interviews were conducted in private offices to ensure confidentiality and instruments were administered by trained interviewers. Participants were provided with a $\$ 5$ non cash incentive in the form of a gift card for their participation. All study procedures were approved by the Institutional Review Board at California State University, Long Beach.

\section{Variables}

The dependent variable is a dichotomous variable of whether the respondents ever used an emergency room in the last 3 months for any reason. The potential independent variables, collected from the RBA, were whether the respondents have ever been in jail or prison for any reason and length of time spent in a jail or prison. The potential mediator variables included use of specific types of drugs (marijuana, opiates such as heroin and nonprescription methadone, crack, cocaine, amphetamine) in the last 30 days, use of injected drugs, and whether the respondent had ever traded sex for drugs or money. Previous work has indicated that these variables are associated with health services usage among at-risk individuals in Los Angeles County (Erlyana, et al. 2014 in press) especially those who access publicly funded HIV and sexually transmitted diseases testing services (Fisher, et al. 2010).

\section{Statistical analysis}

This study utilized mediation analysis to investigate factors that mediated the relationship between history of incarceration and ED use. Use of mediation analysis explains the mechanism through which the independent variable affects the dependent variable (MacKinnon, 2008). A single mediator model determines whether the relationship of the independent variable to the dependent variable was mediated by another third variable. Logistic regression was used because the response (outcome variable) of emergency room use was a binary variable coded at $1=$ any ED use in the past 3 months or $0=$ no ED use in the past three months. Mediation models are developed through a series of regression models where the direct effect of the independent variable are assessed by regression coefficients and standard errors; the effect of the mediator variable is also assessed by regression coefficients and standard errors; and the indirect or mediated effect is of the independent variable on the outcome variable via the mediator variable is then calculated. Because men and women have different patterns of health care use with women consistently reporting more frequent use compared to men, the mediation models were done separately by gender. The mediator variables that were tested in the current study included whether the respondents used opiates or whether the respondents had ever traded sex for money/ drugs. We hypothesized that respondents who used opiates were more likely to use the ED. We also hypothesized that those who traded sex for drugs or money were also more likely to use an ED. We employed the notation used by MacKinnon (2008) (see Figure 1) where c is the direct effect of the IV on the outcome; $\mathrm{b}$ is the effect of the mediator variable on the outcome; a is the effect of the IV on the mediator, and $c^{\prime}$ is the mediated effect of the IV on the outcome via the mediator variable. A $z$ score is then calculated to determine the statistical significance of the mediated or indirect effect. All analyses were conducted in SAS 9.3.

\section{Results \\ Descriptive statistics}

Of the 1341 participants who completed both the RBA and RBFA, 417 (31.1\%) indicated that they had used an emergency room for any reason at least once in the last three months. Compared to those who did not report use of the ED, those who reported use of the ED were more likely to have a history of incarceration $(76.26 \%$ vs. $66.34 \%$, $\left.\chi^{2}(1)=13.31, p=.0003\right)$, a longer average time in jail or prison $(3.75$ years vs. 3.06 years, $t \quad(1243)=-1.88$, $p=.0604)$, and to have ever traded sex for money or drugs (38.73\% vs. $\left.29.01 \%, \chi^{2}(1)=12.68, p=.0004\right)$. Those who reported use of the ED were also more likely to be opiate users $\left(16.78 \%\right.$ vs. $\left.11.73 \%, X^{2}(1)=6.52, p=.0107\right)$ and to have ever received drug treatment $\left(60.42 \%\right.$ vs. $48.56 \%$, $\chi^{2}$ $(1)=16.54, p<.0001)$ than those who did not use an ED (Table 1). The hypothesized relationship of sex trading as a mediator of ED use was not significant for men or women. 


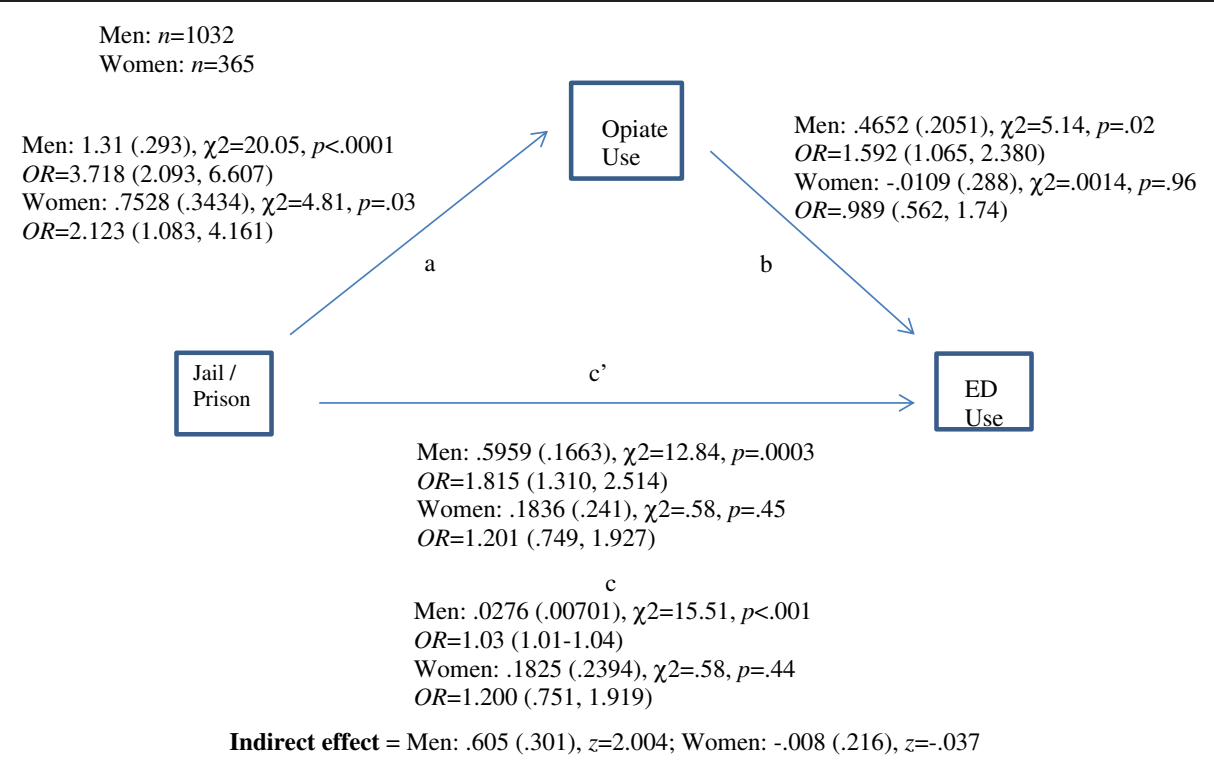

Figure 1 Path diagram for mediation model of emergency room use, previous incarceration and opiate use by gender.

\section{Mediation analysis}

Of 1341 participants of the study, 931 (69.43\%) reported previous incarceration. Figure 1 presents the model of how the effect of past history of incarceration on subsequent ED use is mediated by opiate use. The hypothesis was that those with a history of incarceration were more likely to use opiates, which then led to ED use. Men with a history of incarceration were significantly more likely to use an $\operatorname{ED}\left(\hat{\mathrm{c}}=.0276, \mathrm{~s}_{\hat{\mathrm{c}}}=.0071, \mathrm{X}^{2}=15.51, \mathrm{OR}=\right.$ 1.03). There was a statistically significant effect of history of incarceration on opiate use for men $(a=1.31$ (.293), $\left.\chi^{2}=20.05, p<.0001, \quad \mathrm{OR}=3.718\right)$ and women $\left(a=.7528\right.$ (.3434), $\chi^{2}=4.81, p=.03$, OR $=2.123$ ) however the opiate use was significantly associated with ED use for men only $\left(\mathrm{b}=.4652(.2051), \mathrm{X}^{2}=5.14, p=.02, \mathrm{OR}=\right.$ 1.592). The adjusted effect of past history of incarceration was statistically significant for men $\left(c^{\prime}=.5959\right.$ (.1663), $\chi^{2}=12.84, p=.0003, \mathrm{OR}=1.815$ ) but not for women. This means that the opiate use mediated the effect of past history of incarceration on ED use for men. The total mediated effect (indirect effect) of opiate use on past history of incarceration and ED use was significant for men but not for women ( $\hat{a} b$ (std. err.) $=.605$ (.301), $z=2.004$ (see Figure 1).

\section{Discussion}

This study explored models to determine whether the use of emergency room services post-incarceration is mediated in a meaningful way by a third variable for men or women. As noted, the relationship between history of incarceration and ED use was significant for men but not for women in our sample, in that those with a history of incarceration were more likely to report use of the ED (Figure 1). The relationship for men was mediated by opiate use which suggests that ED use was more prevalent among male opiate-using former prisoners (van Olphen et al. 2006) and heavy illicit drug use has previously been identified as a significant predictor of ED use (French et al. 2011). History of incarceration was significantly associated with opiate use for both men and women, however, from the current study we do not know if drug use occurred only in jail/prison, only during those periods when the participants were not incarcerated, or both. While incarceration was significantly associated with injection drug use, the Anderson model posits multiple vulnerabilities (Calzavara et al. 2003) as pathways to health services usage. The total mediated effect (indirect effect) of opiate use in this study was significant only for men suggesting that opiate use is a vulnerability for men but not for women in terms of ED use.

The relationship between history of incarceration and ED use was not mediated by sex trading for drugs or money for either men or women (data not shown). This was true for sex trading for money or drugs as well as a combination variable of survival sex, which included trading sex for both money and drugs.

This study did find that a history of incarceration was significantly associated with sex trading for drugs or money as suggested by the literature, whereby former inmates were found to be more likely to engage in transactional sex immediately upon release from prisons (Adams et al. 2011) and to engage in high-risk sexual partnerships (Jenness et al. 2011). The study also found that those who traded sex for drugs or money were significantly more likely to report ED use as the literature 
Table 1 Characteristics of ED users vs. non- ED users

\begin{tabular}{|c|c|c|c|c|}
\hline Variables & $\begin{array}{l}\text { Has ever use ED } \\
n=417 \\
\text { Mean (SD) or\% }\end{array}$ & $\begin{array}{l}\text { Never use ED } \\
n=924 \\
\text { Mean (SD) or\% }\end{array}$ & $t, \mathrm{df}$ or $\mathrm{X}^{2}(\mathrm{df})$ & $p$-value \\
\hline Age & $40.8(11.21)$ & $40.5(11.59)$ & $-.47,1338$ & .6381 \\
\hline \multicolumn{5}{|l|}{ Race } \\
\hline Black & 45.19 & 43.29 & $5.33(3)$ & .1488 \\
\hline Whites & 33.17 & 29.33 & & \\
\hline Hispanics & 14.66 & 18.72 & & \\
\hline Others & 6.97 & 8.66 & & \\
\hline Has a history of incarceration & 76.26 & 66.34 & $13.31(1)$ & .0003 \\
\hline Has ever had STIs* & 49.53 & 40.30 & $10.21(1)$ & .0014 \\
\hline Has ever traded sex for drugs or money & 38.73 & 29.01 & $12.68(1)$ & .0004 \\
\hline Opiate use & 16.78 & 11.73 & $6.52(1)$ & .0107 \\
\hline Injection drug use & 28.81 & 23.13 & $5.05(1)$ & .0247 \\
\hline \multicolumn{5}{|l|}{ Income } \\
\hline$<\$ 1,000$ & 78.77 & 66.71 & $18.18(2)$ & .0001 \\
\hline$\$ 1,000-\$ 3,999$ & 18.49 & 24.57 & & \\
\hline$>\$ 3,999$ & 2.74 & 8.71 & & \\
\hline Had paid job, salary, or business & 21.5 & 31.92 & $15.14(1)$ & .0001 \\
\hline On welfare, public assistance & 39.23 & 32.24 & $6.15(1)$ & .0131 \\
\hline Had Social Security, disability & 30.99 & 20.78 & 16.31 & .0001 \\
\hline Heterosexual & 67.69 & 61.59 & $4.68(1)$ & .0305 \\
\hline \multicolumn{5}{|l|}{ Marital status } \\
\hline Single & 53.63 & 63.68 & $13.49(2)$ & .0012 \\
\hline Married & 20.14 & 17.41 & & \\
\hline Separated/divorced & 26.23 & 18.91 & & \\
\hline \multicolumn{5}{|l|}{ Education } \\
\hline Less than High School & 29.84 & 27.19 & $6.64(2)$ & .0361 \\
\hline High School & 37.53 & 32.94 & & \\
\hline Some college or above & 32.63 & 39.87 & & \\
\hline Homeless & 47.04 & 41.04 & $4.28(1)$ & .0386 \\
\hline Female & 32.08 & 22.95 & $12.79(1)$ & .0003 \\
\hline Has ever received drug treatment & 60.42 & 48.56 & $16.54(1)$ & .0001 \\
\hline
\end{tabular}

Note: *include hepatitis B, gonorrhea, syphilis, genital warts (HPV), chlamydia, and genital herpesMen: .5959 (.1663), X2 = 12.84, $p=.0003$.

has reported that sex workers, due to occupational stigma and fear of violent victimization, were less likely to have access to primary health care (Kurtz et al. 2005; Lazarus et al. 2011). However, these relationships, while significant in bivariate analyses were not significant for either men or women when sex trading for either drugs or money, or both, was used in a mediation model.

There are several limitations that need to be noted in this study. First, there is a need to capture information on reasons for use of the ED. This information would be particularly useful to separate cases that are episodes of non-acute medical needs from assault-related or druginvolved incidents, such as overdose. Data on having a regular source of care (outpatient care such as a primary care physician) and health status of the respondents were not available. The current study did not capture variables associated with mental health status, including depression and anxiety, which may influence use of emergency rooms (Sandoval et al. 2010). This study focused on out-of-treatment drug users whose opiate use consisted mainly of heroin and non-prescription methadone. The majority were low income, reporting $\$ 1,000$ or less per month. The findings reported here may not generalize to individuals who are misusing prescription opiates, although it has been suggested in other studies (Reynolds et al. 2000). Lastly, the sample used in this 
study has a relatively higher rate of ED use compared to the general population ( $30 \%$ vs. $20 \%$ ), and most probably is due to an extremely high prevalence of individuals with a history of incarceration (about $70 \%$ of the total sample).

\section{Conclusion}

Future research comparing ED and outpatient care use for previously incarcerated individuals should consider mediation models that control for the health status of the respondents. Continued access to Medicaid (Wakeman et al. 2009) and engaging individuals to use primary care in transition clinics (Wang et al. 2012) should be considered as alternatives to reduce societal burden associated with increasing spending and overcrowding of EDs.

\section{Competing interests}

The authors declare that they have no competing interests.

\section{Authors' contributions}

EE reviewed the literature, analyzed the data to create table 1, and wrote first draft of Background, Methods and Results. DF provided guidance and supervised the entire process, including the use of the mediation model approach and variable selection. GR conducted the mediation analysis, created Figure 1, wrote Discussion section, edited and submitted the manuscript, and performed all revisions. All authors read and approved the final manuscript.

\section{Acknowledgements}

Research reported in this publication was supported by the National Institute of Minority Health and Health Disparities of the National Institutes of Health under award number P20M003942. The content is solely the responsibility of the authors and does not necessarily represent the official views of the National Institutes of Health.

\section{Author details}

${ }^{1}$ Health Care Administration Department, California State University Long Beach, 1250 Bellflower Blvd., Long Beach, CA 90840, USA. ${ }^{2}$ Center for Behavioral Research and Services, California State University Long Beach, 1090 Atlantic Avenue, Long Beach, CA 90813, USA. ${ }^{3}$ Center for Behavioral Research and Services, California State University Long Beach, 1250 Bellflower Blvd., Long Beach, CA 90840, USA.

Received: 3 December 2013 Accepted: 5 March 2014

Published: 25 Mar 2014

\section{References}

Adams, J, Nowels, C, Corsi, K, Long, J, Steiner, JF, \& Binswanger, IA. (2011). HIV risk after release from prison: a qualitative study of former inmates. Journal of Acquired Immune Deficiency Syndromes, 57(5), 429-434. doi:10.1097/ QAl.0b013e31821egf41.

Binswanger, IA, Krueger, PM, \& Steiner, JF. (2009). Prevalence of chronic medical conditions among jail and prison inmates in the USA compared with the general population. Journal of Epidemiology and Community Health, 63(11), 912-919. doi:10.1136/jech.2009.090662.

Binswanger, IA, Stern, MF, Deyo, RA, Heagerty, PJ, Cheadle, A, Elmore, JG, \& Koepsell, TD. (2007). Release from prison - a high risk of death for former inmates. New England Journal of Medicine, 356(2), 157-165. doi:10.1056/NEJMsa064115.

Boys, A, Farrell, M, Bebbington, P, Brugha, T, Coid, J, Jenkins, R, \& Singleton, N. (2002). Drug use and initiation in prison: results from a national prison survey in England and Wales. Addiction, 97(12), 1551-1560.

Calzavara, LM, Burchell, AN, Schlossberg, J, Myers, T, Escobar, M, Wallace, E, \& Millson, M. (2003). Prior opiate injection and incarceration history predict injection drug use among inmates. Addiction, 98(9), 1257-1265.

Cherpitel, CJ, \& Ye, Y. (2008). Drug use and problem drinking associated with primary care and emergency room utilization in the US general population: data from the 2005 national alcohol survey. Drug and Alcohol Dependence, 97(3), 226-230.
Davis, LM, \& Pacchiana, S. (2004). Health profile of the state prison population and returning offenders: public health challenges. Journal of Correctional Health Care, 10(3), 303-331. doi:10.1177/107834580301000305.

Dowling-Guyer, S, Johnson, ME, Fisher, DG, Needle, R, Watters, J, Andersen, M, \& Rhodes, F. (1994). Reliability of drug users' self-reported HIV risk behaviors and validity of self-reported recent drug use. Assessment, 1(4), 383-392.

El-Bassel, N, Gilbert, L, Wu, E, Chang, M, Gomes, C, Vinocur, D, \& Spevack, T. (2007). Intimate partner violence prevalence and HIV risks among women receiving care in emergency departments: Implications for IPV and HIV screening. Emergency Medicine Journal, 24(4), 255-259.

Epperson, MW, Platais, I, Valera, P, Barbieri, R, Gilbert, L, \& El-Bassel, N. (2009). Fear, trust, and negotiating safety HIV risks for black female defendants. Affilia, 24(3), 257-271

Erlyana, E, Fisher, DG, Reynolds, GL, \& Janson, ME. (2014). Medical service use among recipient of HIV prevention services in Los Angeles County. Journal of Human and Health Service Administration, 36(4), 497-518. Spring 2014.

Fazel, S, Bains, P, \& Doll, H. (2006). Substance abuse and dependence in prisoners: a systematic review. Addiction, 101(2), 181-191. doi:10.1111/j.13600443.2006.01316.x.

Fisher, DG, Milroy, ME, Reynolds, GL, Klahn, JA, \& Wood, MM. (2004a). Arrest history among men and sexual orientation. Crime \& Delinquency, 50(32), 32-42.

Fisher, DG, Reynolds, GL, Jaffe, A, \& Perez, MJ. (2006). Hepatitis and human immunodeficiency virus co-infection among injection drug users in Los Angeles County, California. Journal of Addictive Diseases, 25(2), 25-32.

Fisher, DG, Reynolds, GL, Wood, MM, \& Johnson, ME. (2004b). Reliability of arrest and incarceration questions on the risk behavior assessment. Crime \& Delinquency, 50(1), 24-31. doi:10.1177/0011128703258872.

Fisher, DG, Wishart, D, Reynolds, GL, \& Edwards, JW. (2010). HIV service utilization in Los Angeles County, California. AIDS \& Behavior, 14(2), 440-447. doi:10.1007/s10461-008-9500-3.

French, MT, Fang, H, \& Balsa, Al. (2011). Longitudinal analysis of changes in illicit drug use and health services utilization. Health Services Research, 46, 877-899.

French, MT, McGeary, KA, Chitwood, DD, \& McCoy, CB. (2000). Chronic illicit drug use, health services utilization and the cost of medical care. Social Science \& Medicine, 50(12), 1703-1713.

Freudenberg, N, Daniels, J, Crum, M, Perkins, T, \& Richie, B. (2008). Coming home from jail: the social and health consequences of community reentry for women, male adolescents, and their families and communities. American Journal of Public Health, 98(9 Suppl), S191-S202. doi:98/Supplement_9/S191.

Garrity, TF, Hiller, ML, Staton, M, Webster, JM, \& Leukefeld, CG. (2002). Factors predicting illness and health services use among male Kentucky prisoners with a history of drug abuse. The Prison Journal, 82(3), 295-313. doi:10.1177/ 003288550208200301.

Gilbert, L, El-Bassel, N, Chang, M, Wu, E, \& Roy, L. (2012). Substance use and partner violence among urban women seeking emergency care. Psychology of Addictive Behaviors, 26, 226-235.

Hawkins, AS, O'Keefe, AM, \& James, X. (2010). Health care access and utilization among ex-offenders in Baltimore: implications for policy. Journal of Health Care for the Poor and Underserved, 21(2), 649-665.

Jenness, SM, Kobrak, P, Wendel, T, Neaigus, A, Murrill, CS, \& Hagan, H. (2011). Patterns of exchange sex and HIV infection in high-risk heterosexual men and women. Journal of Urban Health, 88(2), 329-341. doi:10.1007/s11524-010-9534-5.

Johnson, ME, Fisher, DG, Montoya, I, Booth, R, Rhodes, F, Andersen, M, \& Williams, M. (2000). Reliability and validity of not-in-treatment drug users' follow-up self-reports. AIDS and Behavior, 4(4), 373-380.

Kanato, M. (2008). Drug use and health among prison inmates. Current Opinion in Psychiatry, 21(3), 252-254. doi:10.1097/YCO.0b013e3282fc985.

Kerr, T, Wood, E, Grafstein, E, Ishida, T, Shannon, K, Lai, C, \& Tyndall, MW. (2005). High rates of primary care and emergency department use among injection drug users in Vancouver. Journal of Public Health, 27(1), 62-66. doi:10.1093/ pubmed/fdh189.

Khan, MR, Doherty, IA, Schoenbach, VJ, Taylor, EM, Epperson, MW, \& Adimora, AA. (2009). Incarceration and high-risk sex partnerships among men in the United States. Journal of Urban Health, 86(4), 584-601. doi:10.1007/s11524-009-9348-5.

Kulkarni, S, Baldwin, S, Lightstone, A, Gelberg, L, \& Diamant, A. (2010). Is incarceration a contributor to health disparities? Access to care of formerly incarcerated adults. Journal of Community Health, 35(3), 268-274. doi:10.1007/ s10900-010-9234-9.

Kurtz, SP, Surratt, HL, Kiley, MC, \& Inciardi, JA. (2005). Barriers to health and social services for street-based sex workers. Journal of Health Care for the Poor and Underserved, 16(2), 345-361. 
LaMoure, J, Meadows, R, Mondschein, H, \& Llewellyn, S. (2010). Interviewing male and female jail inmates sentenced for drug offenses: findings and implications. Criminal Justice Studies, 23(1), 85-95.

Lazarus, L, Deering, KN, Nabess, R, Gibson, K, Tyndall, MW, \& Shannon, K. (2011). Occupational stigma as a primary barrier to health care for street-based sex workers in Canada. Culture, Health \& Sexuality, 14(2), 139-150. doi:10.1080/ 13691058.2011.628411.

Leukefeld, CG, Hiller, ML, Webster, JM, Tindall, MS, Martin, SS, Duvall, J, \& Garrity, TF. (2006). A prospective examination of high-cost health services utilization among drug using prisoners reentering the community. The Journal of Behavioral Health Services \& Research, 33(1), 73-85. doi:10.1007/s11414-005-9006-y.

Leukefeld, C, Logan, T, Martin, S, Durvis, R, \& Farabee, D. (1998). A health services use framework for drug-abusing offenders. Am Behav Sci, 41, 1123-1135.

Lloyd-Smith, E, Kerr, T, Hogg, RS, Li, K, Montaner, JS, \& Wood, E. (2005). Prevalence and correlates of abscesses among a cohort of injection drug users. Harm Reduction Journal, 2, 24. doi:10.1186/1477-7517-2-24.

MacKinnon, DP. (2008). Introduction to Statistical Mediation Analysis. 711 Third Avenue, New York, NY 10017: Taylor \& Francis Group, LLC.

Marshall, BDL, Grafstein, E, Buxton, JA, Qi, J, Wood, E, Shoveller, JA, \& Kerr, T. (2012). Frequent methamphetamine injection predicts emergency department utilization among street-involved youth. Public Health (Elsevier), $126,47-53$

Mateyoke-Scrivner, A, Webster, JM, Hiller, ML, Staton, M, \& Leukefeld, C. (2003). Criminal history, physical and mental health, substance abuse, and services use among incarcerated substance abusers. Journal of Contemporary Criminal Justice, 19(1), 82-97. doi:10.1177/1043986202239743.

McConville, S, \& Lee, H. (2008). Emergency department care in California. In HP Johnson (Ed.), California Counts: Population Trends and Profiles (Vol. 10 No. 1) (Vol. 10). San Francisco, CA: Public Policy Institute of California.

Mears, DP, \& Cochran, JC. (2012). U.S. prisoner reentry health care policy in international perspective: service gaps and the moral and public health implications. The Prison Journal, 92(2), 175-202. doi:10.1177/ 0032885512438845 .

Merrall, ELC, Kariminia, A, Binswanger, IA, Hobbs, MS, Farrell, M, Marsden, J, \& Bird, SM. (2010). Meta-analysis of drug' related deaths soon after release from prison. Addiction, 105(9), 1545-1554.

Meyer, JP, Jingjun, Q, Chen, NE, Larkin, GL, Altice, FL, \& Cameron, DW. (2012). Emergency department use by released prisoners with HIV: an observational longitudinal study. PLOS ONE, 7, 1-10

Narevic, E, Garrity, TF, Schoenberg, NE, Hiller, ML, Webster, JM, Leukefeld, CG, \& Tindall, MS. (2006). Factors predicting unmet health services needs among incarcerated substance users. Substance Use \& Misuse, 41(8), 1077-1094. doi:10.1080/10826080600692167.

Nchs, NCFHS. (2013). Health, United States, 2012: With Special Feature on Emergency Care. Hyattsville, MD: National Center for Health Statistics.

Owens, PL, Barrret, ML, Gibson, T, Andrews, B, Weinick, RM, \& Mutter, RL. (2010). Emergency department care in the United States: a profile of national data sources. The Practice of Emergency Medicine, 56(2), 150-165.

Napper, LE, Fisher, DG, Reynolds, GL, \& Johnson, ME. (2010). HIV risk behavior selfreport reliability at different recall periods. AIDS Behav, 14(1), 152-161.

Reynolds, GL, Wells, RS, Fisher, DG, \& Cagle, HH. (2000). Health services usage by Alaskan injection drug users. Journal of Ethnicity in Substance Abuse, 5(2), 2006.

Sandoval, E, Smith, S, Walter, J, Schuman, SAH, Olson, MP, Striefler, R, \& Hickner, J. (2010). A comparison of frequent and infrequent visitors to an urban emergency department. The Journal of emergency medicine, 38(2), 115-121.

Schnittker, J, \& John, A. (2007). Enduring stigma: the long-term effects of incarceration on health. Journal of Health and Social Behavior, 48(2), 115-130.

Stein, MD, \& Anderson, B. (2003). Injection frequency mediates health service use among persons with a history of drug injection. Drug and Alcohol Dependence, 70(2), 159-168.

Van Olphen, J, Eliason, MJ, Freudenberg, N, \& Barnes, M. (2009). Nowhere to go: how stigma limits the options of female drug users after release from jail. Substance Abuse Treatment and Prevention Policy, 4, 10. doi:10.1186/1747-597X-4-10.

Van Olphen, J, Freudenberg, N, Fortin, P, \& Galea, S. (2006). Community reentry: perceptions of people with substance use problems returning home from New York City jails. Journal of Urban Health, 83(3), 372-381. doi:10.1007/ s11524-006-9047-4.

Wakeman, SE, McKinney, ME, \& Rich, JD. (2009). Filling the gap: the importance of Medicaid continuity for former inmates. Journal of General Internal Medicine, 24(7), 860-862. doi:10.1007/s11606-009-0977-x.
Wang, E, \& Green, J. (2010). Incarceration as a key variable in racial disparities of asthma prevalence. BMC Public Health, 10(1), 290.

Wang, EA, Hong, CS, Shavit, S, Sanders, R, Kessell, E, \& Kushel, MB. (2012). Engaging individuals recently released from prison into primary care: a randomized trial. American Journal of Public Health, 102(9), e22-e29. doi:10.2105/AJPH.2012.300894.

Webster, JM, Leukefeld, CG, Tindall, MS, Hiller, ML, Garrity, TF, \& Narevic, E. (2005). Lifetime health services use by male drug-abusing offenders. The Prison Journal, 85(1), 50-64. doi:10.1177/0032885504274290.

Weiser, SD, Dilworth, SE, Neilands, TB, Cohen, J, Bangsberg, DR, \& Riley, ED. (2006) Gender-specific correlates of sex trade among homeless and marginally housed individuals in San Francisco. Journal of Urban Health, 83(4), 736-740. doi:10.1007/s11524-005-9019-0.

Wilper, AP, Woolhandler, S, Boyd, JW, Lasser, KE, McCormick, D, Bor, DH, \& Himmelstein, DU. (2009). The health and health care of US prisoners: results of a nationwide survey. American Journal of Public Health, 99(4), 666-672. doi:10.2105/AJPH.2008.144279.

\section{$10.1186 / 2194-7899-2-5$}

Cite this article as: Erlyana et al:: Emergency room use after being released from incarceration. Health and Justice 2014, 2:5

\section{Submit your manuscript to a SpringerOpen ${ }^{\odot}$ journal and benefit from:}

- Convenient online submission

- Rigorous peer review

- Immediate publication on acceptance

- Open access: articles freely available online

- High visibility within the field

- Retaining the copyright to your article

Submit your next manuscript at $>$ springeropen.com 